\title{
Effect of Strain Rate on Hot Ductility of a Duplex Stainless Steel
}

\author{
Zhenhua Wang $\mathbb{D}^{1,2,3}$ Wenyuan $M a \mathbb{D}^{1},{ }^{1}$ and Chengming Wang $\mathbb{D}^{3}$ \\ ${ }^{1}$ School of Mechanical Engineering, Yanshan University, Qinhuangdao 066004, China \\ ${ }^{2}$ State Key Laboratory of Metastable Materials Science and Technology, Yanshan University, Qinhuangdao 066004, China \\ ${ }^{3}$ HBIS Group Technology Research Institute, Shijiazhuang 050023, China
}

Correspondence should be addressed to Zhenhua Wang; wangzhenhua@ysu.edu.cn

Received 26 March 2019; Accepted 25 July 2019; Published 5 August 2019

Academic Editor: Hongtao Zhu

Copyright (c) 2019 Zhenhua Wang et al. This is an open access article distributed under the Creative Commons Attribution License, which permits unrestricted use, distribution, and reproduction in any medium, provided the original work is properly cited.

\begin{abstract}
Duplex stainless steels (DSSs) often have bad hot workability. In this study, specimens of 2205 DSS were hot tensioned over a strain rate range from $0.005 \mathrm{~s}^{-1}$ to $50 \mathrm{~s}^{-1}$ to examine the hot ductility. The crack morphology was observed, and the dependence of hot ductility on the strain rate was analyzed. From $0.005 \mathrm{~s}^{-1}$ to $0.5 \mathrm{~s}^{-1}$, both the total elongation and the reduction in area increased with the strain rate. The reduction in area exhibited a small decrease when the strain rate was greater than $0.5 \mathrm{~s}^{-1}$. More than $85 \%$ of cracks formed between the ferrite and austenite, and no less than $70 \%$ of crack tips propagated between the ferrite and austenite. When the strain rate was increased from $0.005 \mathrm{~s}^{-1}$ to $0.5 \mathrm{~s}^{-1}$, dynamic recrystallization was promoted in the austenite, and the number fraction of low-angle grain boundaries in the ferrite was improved. The higher strain rate reduced the difference between ferrite and austenite in hardness, which improved the hot ductility. For 2205 DDS, the suggested strain rate is $0.5 \mathrm{~s}^{-1}$ and above to avoid surface and edge cracking during hot forging or hot rolling. The findings will be of value for the understanding of hot ductility of DSSs and other dual-phase alloys.
\end{abstract}

\section{Introduction}

Duplex stainless steels (DSSs) possess the advantages of both ferrite and austenite, such as high strength, toughness, and excellent local and stress corrosion resistances [1]. DSSs have low nickel content, which lowers their cost and helps to ensure price stability [2]. Therefore, DDSs are widely used in chemical, marine, paper, water treatment, transport, and energy industries. However, DDSs often have poor hot workability and the use of DDSs is restricted [3].

Many factors affecting the hot ductility of DDSs have been extensively studied. Feng et al. [4] compared the formation mechanism of the hot rolling crack in 2205 and 2101 DSSs. Their results showed that the difference between ferrite and austenite in microhardness was the main reason of cracking. The larger the difference was, the more serious the cracking was. The effects of the $\gamma^{\prime}$ phase on the hot ductility of DDSs are complex. Fan et al. [5] reported that the $\gamma^{\prime}$ phase in the ferrite was the recrystallization of ferrite and markedly improved the hot ductility. In contrast, Patra et al. [6] found that $\gamma^{\prime}$ particles were detrimental to the hot workability of DDS because $\gamma^{\prime}$ particles obstructed the dislocation motion and restricted the plastic deformation of ferrite. Besides the $\gamma^{\prime}$ particles, brittle sigma-phase particles precipitated at the phase boundary affect the hot ductility of DDS seriously. Zhao et al. [7] found that these particles were the potential nucleation sites and propagation paths of cracks. These studies have enhanced our understanding of the hot ductility of DSSs.

Strain rate is one of the important factors influencing the hot ductility of DDSs. Flow instability, including microcracking, occurred at high strain rates $\left(\geq 1 \mathrm{~s}^{-1}\right)$ during hot compression for 2101 lean DSS [8]. Similar result was obtained by $\mathrm{Ma}$ et al. [9], who reported that microcracks formed at a high strain rate condition $\left(10 \mathrm{~s}^{-1}\right)$ during hot compression of 2205 DSS. However, Faccoli and Roberti [10] observed that cracks formed more easily at lower strain rates in 2205 DSS during hot tension tests. Thus, it still remains unclear whether the high strain rate is beneficial or detrimental to the hot ductility of DSSs. 
In this study, 2205 DSS was selected. After solution treatment, 2205 DSS was hot tensioned over a large strain rate range from $0.005 \mathrm{~s}^{-1}$ to $50 \mathrm{~s}^{-1}$. The hot ductility was examined. The crack morphology was observed, and the dependence of hot ductility on the strain rate was analyzed. The findings are intended to be of value for the understanding of hot ductility of DSSs and other dual-phase metal alloys.

\section{Materials and Methods}

The tested 2205 DSS was a commercially available bar with a diameter of $50 \mathrm{~mm}$. Its chemical composition was C $0.03 \%$, Cr 22.4\%, Ni 5.1\%, Mn 1.2\%, Si 0.85\%, Cu 0.18\%, V 0.17\%, and Mo 2.8\% (wt.\%). The tested 2205 DSS solution was heat treated at $1373 \mathrm{~K}$ for $1 \mathrm{~h}$, and the microstructure etched for $10 \mathrm{~s}$ with aqua regia is shown in Figure 1. The dark areas are austenite, and the light ones are ferrite. Hot tensile specimens $(6 \mathrm{~mm}$ in diameter and $120 \mathrm{~mm}$ in length) were machined. Hot tension tests were conducted using a Gleeble 3800 physical simulator. The deformation temperature was $1373 \mathrm{~K}$, and the strain rates were $0.005,0.05,0.5,5$, and $50 \mathrm{~s}^{-1}$. A gage length of $12 \mathrm{~mm}$ was used to determine the strain. Some specimens were tensioned to be broken, and other specimens were tensioned to a strain of 0.4 (but were not broken).

Unbroken specimens were cut parallel to the tension direction. The observation site was in the center of the specimen. Electron backscatter diffraction (EBSD) analyses were conducted in a Hitachi 3400 scanning electron microscope with TSL OIM-Analysis software to investigate the specimens. The spatial resolution was $1 \mu \mathrm{m}$, and the misorientation detection limit was $1^{\circ}$. The EBSD maps indicated high-angle grain boundaries (HAGBs, misorientations $\geq 15^{\circ}$, shown as black lines), twin boundaries (TBs, shown as red lines), and low-angle grain boundaries (LAGBs, $2^{\circ} \leq$ misorientations $<15^{\circ}$, shown as grey lines). Cracks exhibit low confidence indices $(<0.1)$. Therefore, points that have low confidence indices were filtered.

\section{Results}

3.1. Flow Behavior and Hot Ductility. The flow curves of the specimens tensioned at different strain rates are shown in Figure 2. The deformation resistance increased with the increasing strain rate. The curve at $0.005 \mathrm{~s}^{-1}$ exhibits stable stress. At $0.05 \mathrm{~s}^{-1}$, the material presents a slowly continuous softening behavior after the peak stress. The softening speed becomes very quick at $0.5 \mathrm{~s}^{-1}$ and above. In the strain rate range of $0.005-0.5 \mathrm{~s}^{-1}$, the total elongation increases with the strain rate. The total elongations for specimens deformed at $0.5-50 \mathrm{~s}^{-1}$ are similar.

The effect of the strain rate on the reduction in area is shown in Figure 3. From $0.005 \mathrm{~s}^{-1}$ to $0.5 \mathrm{~s}^{-1}$, the reduction in area continuously increased from $77 \%$ to $90 \%$. The reduction in area exhibits a slight decrease when the strain rate is greater than $0.5 \mathrm{~s}^{-1}$. Obviously, the hot ductility of 2205 DSS is the best at $0.5 \mathrm{~s}^{-1}$.

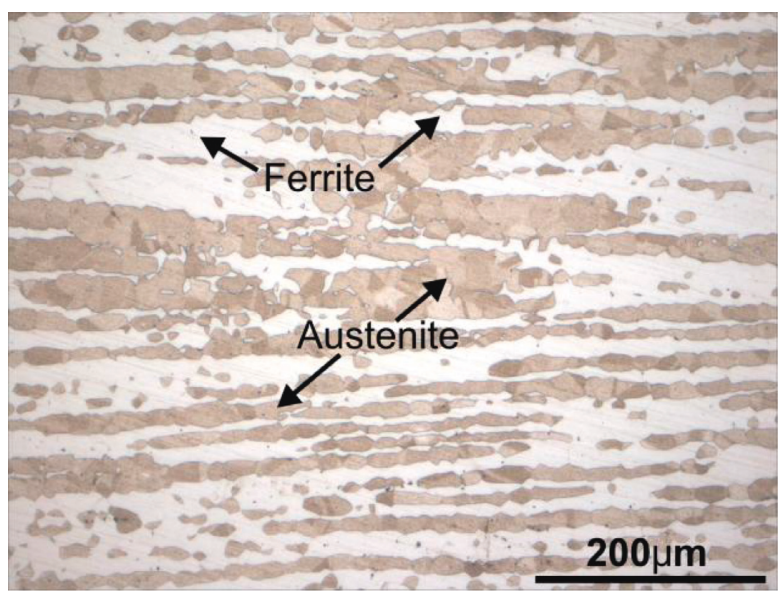

Figure 1: Microstructure of 2205 DSS held at $1373 \mathrm{~K}$ for $1 \mathrm{~h}$.

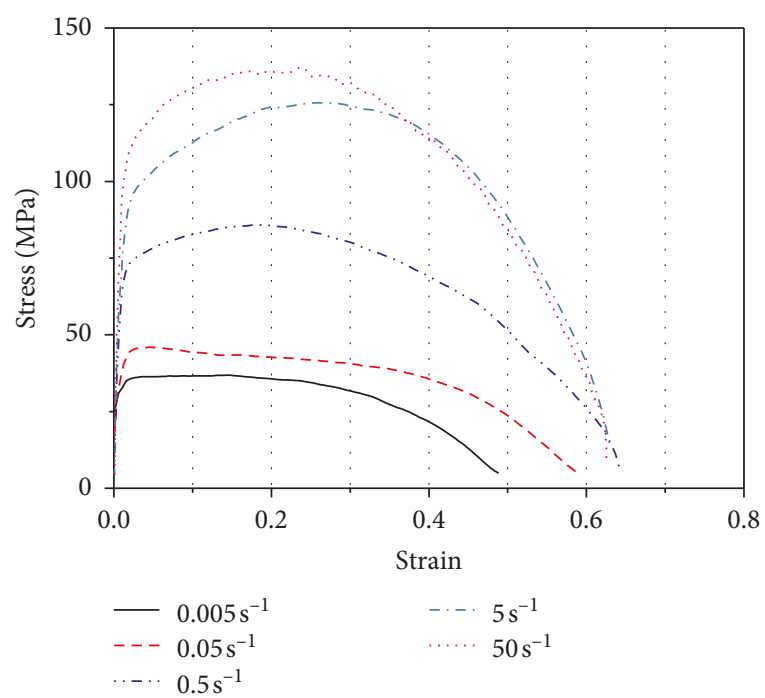

FIgURE 2: Tensile flow curves of 2205 DSS.

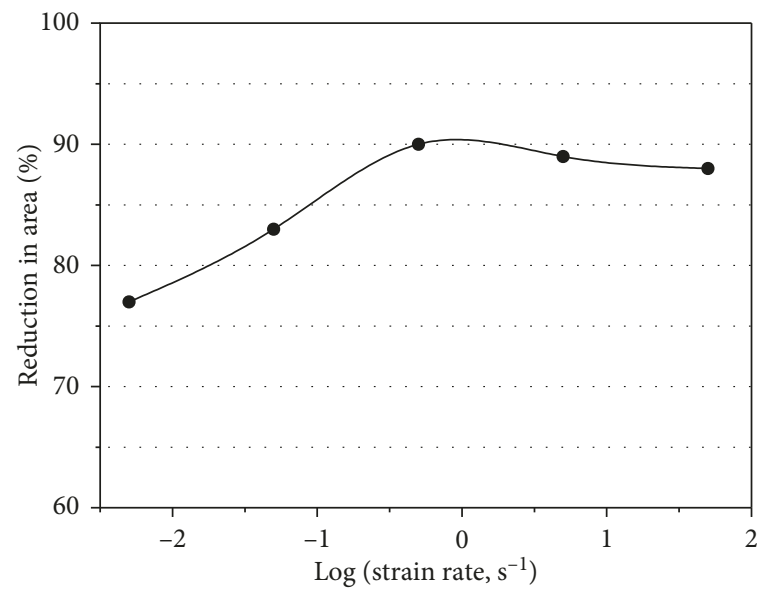

Figure 3: Dependence of reduction in area on the strain rate.

3.2. Tensile Strained Microstructure. To observe the microstructure difference between specimens, strain rates of $0.005 \mathrm{~s}^{-1}, 0.05 \mathrm{~s}^{-1}$, and $0.5 \mathrm{~s}^{-1}$ were selected. The microstructure of specimens strained at different strain rates to 0.4 is shown in Figure 4. In Figure 4(a) $\left(0.005 \mathrm{~s}^{-1}\right)$, a large 

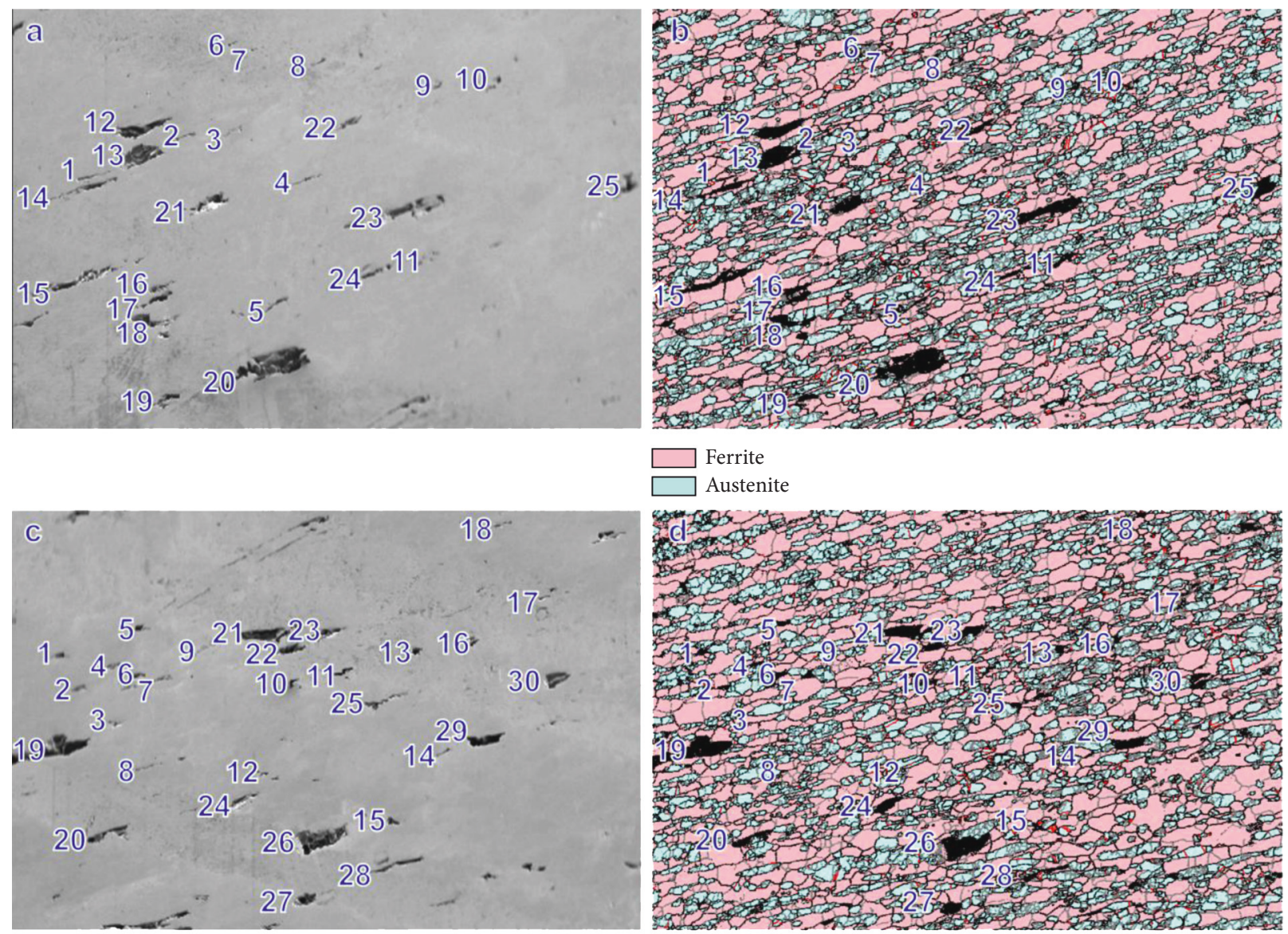

Ferrite
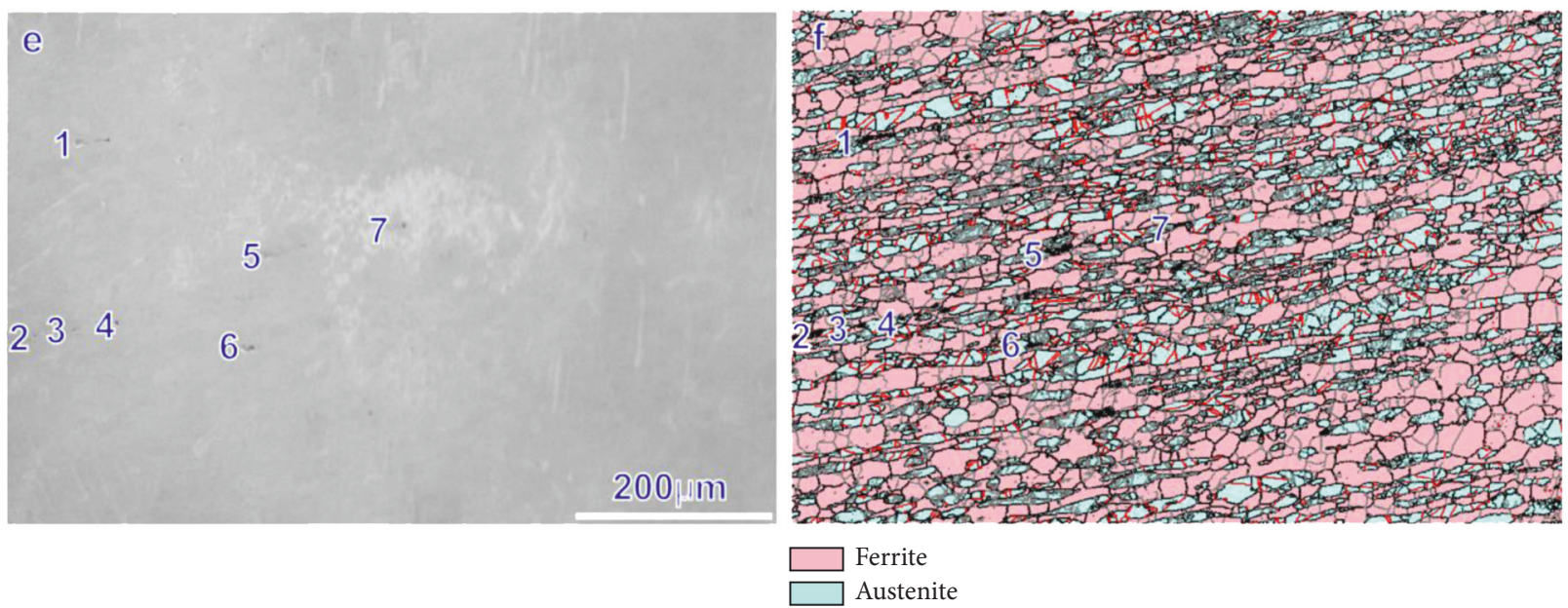

FiguRE 4: Microstructure of specimens strained at different strain rates to 0.4. (a, b) $0.005 \mathrm{~s}^{-1}$; (c, d) $0.05 \mathrm{~s}^{-1}$; (e, f) $0.5 \mathrm{~s}^{-1}$. (a), (c), and (e) are SEM images, and (b), (d), and (f) are corresponding phase maps. The horizontal direction is the tensile axis.

number of cracks can be seen, and their propagation direction is basically parallel to the tensile axis. These cracks are labeled with numbers for discussion here. In the corresponding phase map (Figure 4(b)), some LAGBs are distributed in both the ferrite and austenite. The phase fractions of ferrite and austenite are $59 \%$ and $41 \%$, respectively. A small amount of TBs appeared in the austenite. The small cracks (1-11) are considered as newly formed cracks, and the large cracks (12-25) are considered as propagated cracks. The locations of small cracks are considered to mark crack-forming positions. Cracks 1,4 , and 8 formed between ferrite grains. Cracks 2, 3, 5-7, and 9-11 formed between ferrite and austenite. No crack formed between austenite grains. The large crack tips were used to identify the crack propagation path. It should be noted that each crack may have several tips. Cracks 12, 14, and 21-23 
have tips propagated between ferrite grains. Cracks 13 and 15-25 have tips propagated between ferrite and austenite. No crack tips propagated between austenite grains.

When the strain rate is up to $0.05 \mathrm{~s}^{-1}$ (Figures $4(\mathrm{c})$ and $4(\mathrm{~d}))$, the number of TBs is larger than the case in Figure 4 (b) $\left(0.005 \mathrm{~s}^{-1}\right)$. The cracking conditions are similar for these two specimens. In Figure 3(d), cracks 3 and 14 formed between ferrite grains. Cracks 1, 2, 4-13, and 15-18 formed between ferrite and austenite. No cracks formed between austenite grains. Cracks 20, 22, 26, and 30 have tips propagated between ferrite grains. Cracks 19-30 have tips propagated between ferrite and austenite. No crack tips propagated between austenite grains. The phase fractions of ferrite and austenite are $61 \%$ and $39 \%$, respectively.

When the strain rate is up to $0.5 \mathrm{~s}^{-1}$, a great number of TBs appear in the austenite (Figure 4(f)). The number of cracks in Figure 4(e) is much lower than those in Figures 4(a) and 4(c), and only several small cracks are found. Most of these cracks formed between ferrite and austenite (Figure 4(f)). The phase fractions of ferrite and austenite are $60 \%$ and $40 \%$, respectively.

Figure 5 presents the distribution of misorientation angles in specimens tension tested at $0.005 \mathrm{~s}^{-1}, 0.05 \mathrm{~s}^{-1}$, and $0.5 \mathrm{~s}^{-1}$ to a strain of 0.4 . The number fraction of LAGBs in austenite decreased with the increasing strain rate (Figure 5(a)). The number fraction of TBs (around $60^{\circ}$ ) increased with the increasing strain rate, especially when the strain rate was beyond $0.05 \mathrm{~s}^{-1}$. A large number of TBs indicate sufficient dynamic recrystallization. This is consistent with the phenomenon in the corresponding flow curves, where the softening speed increases with the increasing strain rate (Figure 2). Opposite to the case in austenite, the number fraction of LAGBs increased with the increasing strain rate in ferrite (Figure 5(b)).

\section{Discussion}

In this study, more than $85 \%$ of cracks are formed between ferrite and austenite and no less than $70 \%$ the crack tips propagated between ferrite and austenite. Therefore, the hot ductility of 2205 DSS mainly depends on the deformation and softening mechanisms of both ferrite and austenite.

It is well known that dynamic recrystallization usually occurs during hot deformation, especially under conditions of high temperature and low strain rate, but Wang et al. [11] found that appreciable dynamic recovery occurred at low strain rates $\left(0.001 \mathrm{~s}^{-1}\right)$ and high deformation temperatures $(1373 \mathrm{~K})$. According to Wang et al. [11], a lower strain rate is beneficial for dislocations to climb and form dislocation walls and LAGBs; dynamic recrystallization was inhibited under very low strain rate conditions. In addition, DehghanManshadi and Hodgson [12] observed that dynamic recrystallization kinetics in the austenite phase of DSS were much lower than that in austenitic steel. These two studies tell us that a higher strain rate inhibits dynamic recovery and adds more energy into the material and then benefits dynamic recrystallization in the austenite phase of the DSS. The higher strain rate did not provide enough time for ferrite to recover sufficiently, and then the number fraction of LAGBs increases (Figure 5(b)).

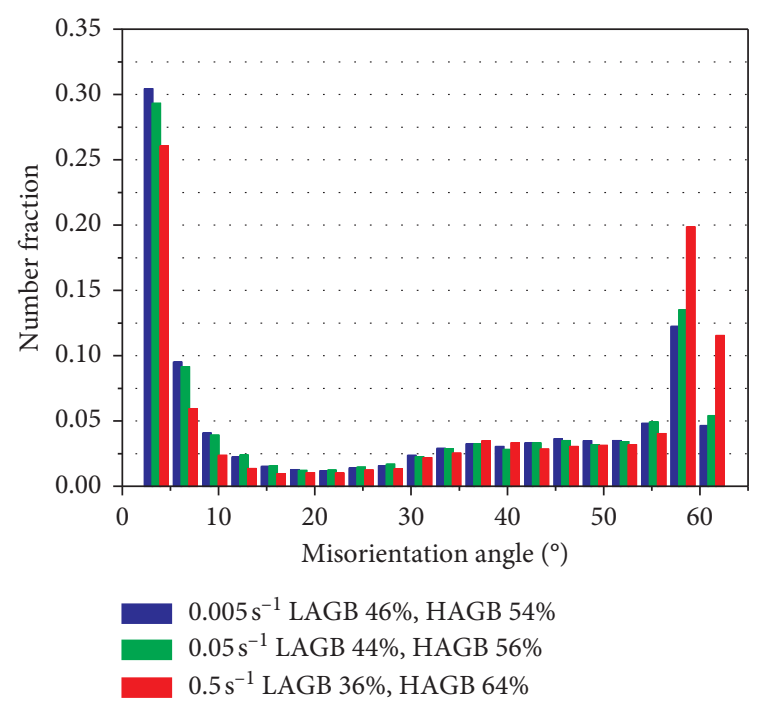

(a)

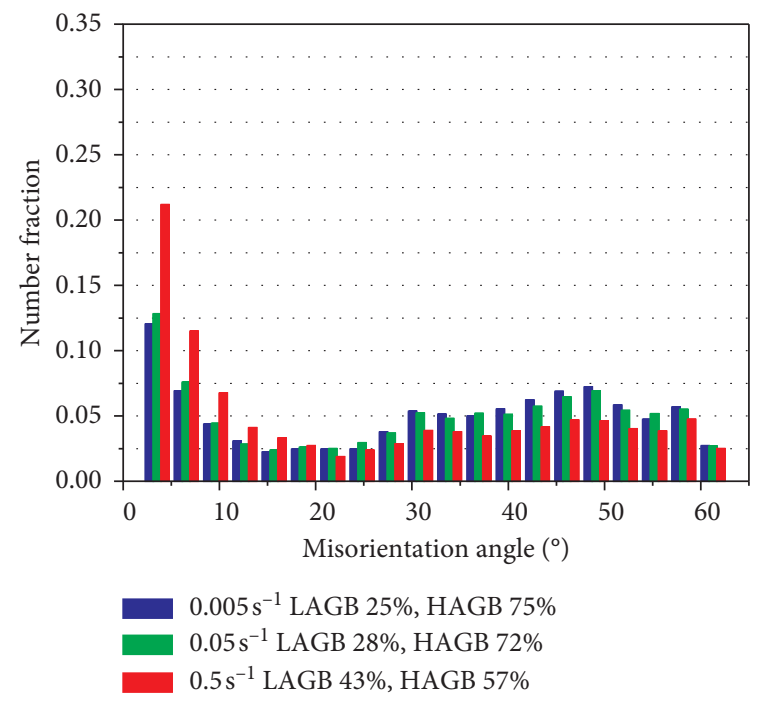

(b)

FIGURE 5: Distribution of misorientation angles in (a) austenite and (b) ferrite.

Under a given bulk strain condition, the strain partition is nonuniform in the duplex-phase material, with more strain distributed in the soft phase. The interfaces between soft and hard phases are the primary sites for the nucleation of cracks owing to strain incompatibility. The larger the hardness difference between soft and hard phases, the higher the cracking tendency. Dynamic recrystallization is the most effective mechanism for softening the strained microstructure. In this study, when the strain rate increased from $0.005 \mathrm{~s}^{-1}$ to $0.5 \mathrm{~s}^{-1}$, dynamic recrystallization "softened" the austenite phase. In contrast, the ferrite is "hardened" under higher strain rate conditions. Higher strain rate lowers the difference between ferrite and austenite in microhardness. Therefore, the hot ductility was improved. This is consistent with the results found by Feng et al. [4], as mentioned in Introduction.

Figure 6 shows the grain orientation spread (GOS) maps of specimens deformed at different strain rates to 0.4 . In the 

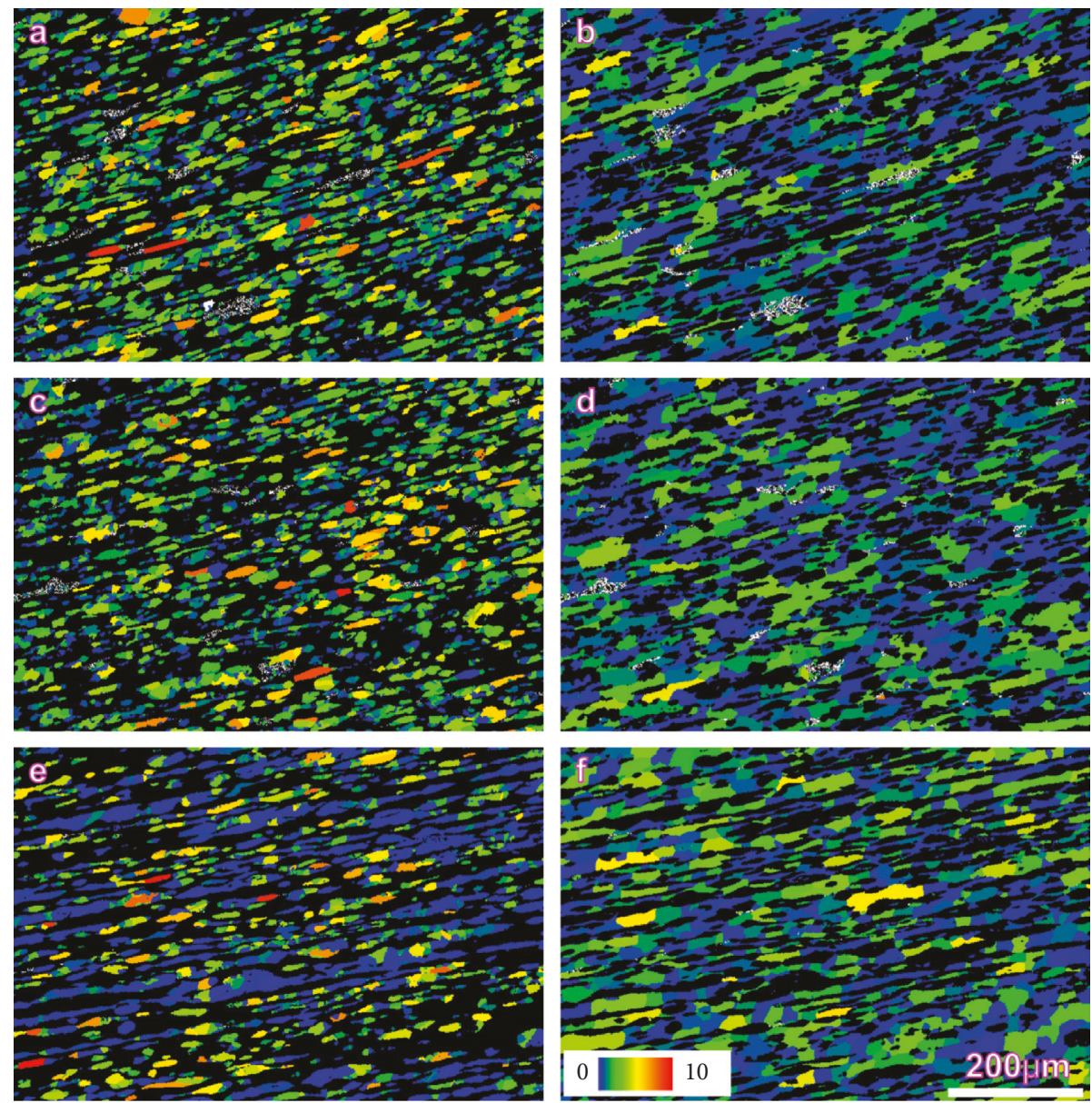

FIGURE 6: GOS maps of specimens strained at different strain rates to 0.4. (a, b) $0.005 \mathrm{~s}^{-1}$; (c, d) $0.05 \mathrm{~s}^{-1}$; (e, f) $0.5 \mathrm{~s}^{-1}$. (a), (c), and (e) are austenite phase, and (b), (d), and (f) are ferrite phase. The horizontal direction is the tensile axis.

GOS images, the grains are shaded using different colors. The basic colors blue, green, yellow, and red represent strains from lowest to highest. The GOS of austenite in the specimen strained at $0.005 \mathrm{~s}^{-1}$ is similar with that at $0.05 \mathrm{~s}^{-1}$. A large number of blue austenite grains (low strained grains) appear in Figure 6(e). Based on above results, it can be known that they are dynamic recrystallization grains. However, for the ferrite phase, some yellow grains (highly strained grains) appear (in Figure 6(f)). The dynamic recovery is inadequate in these yellow grains. Figure 7 shows the relationship between average GOS and strain rate. Obviously, the difference between austenite and ferrite in average GOS decreases with the increasing strain rate. This is consistent with the above analysis about the hardness difference between these two phases.

In other metal alloys, the microhardness differences between phases or regions also have significant influence on the hot ductility. Wong et al. [13] proposed that large deformed grains were deformed less readily than the soft dynamic recrystallization regions. According to Wong et al. [13], internal cracks can form in the AZ31 alloy between deformed and recrystallized grains. This is similar to the case observed by Wang et al. [11], where crack nucleation sites are mainly between "hard" parent grains and "soft" necklace dynamic recrystallization grains.

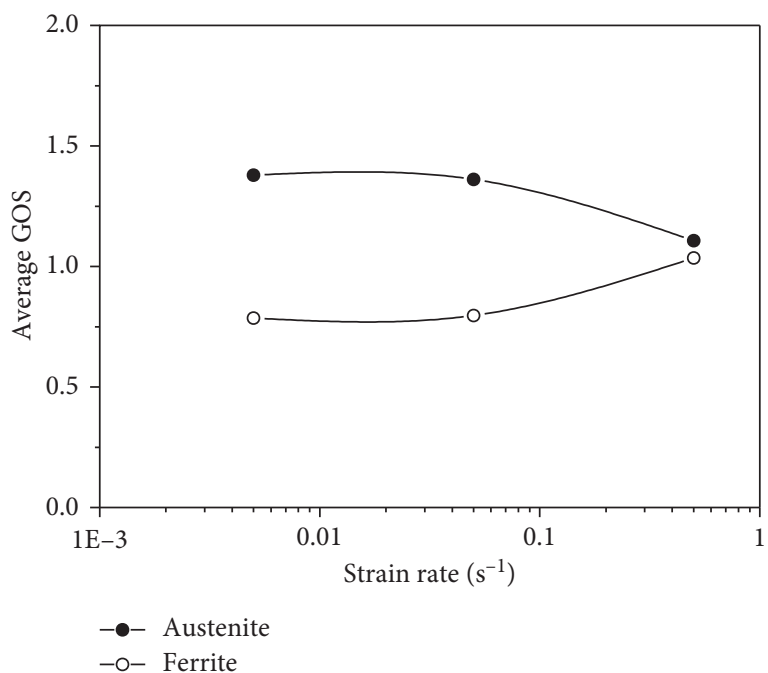

Figure 7: Relationship between average GOS and strain rate.

In this study, the initial microstructure of 2205 DSS was rolled and fine. If the initial microstructure was coarse, for example, in a cast state, the hot ductility would be reduced and the strain rate effect would be more obvious. For 2205 DDS, the suggested strain rate is $0.5 \mathrm{~s}^{-1}$ and above to avoid 
surface and edge cracking during hot forging or hot rolling. For other DDSs and duplex-phase materials, the working parameters, for example, strain rate and temperature, should be selected to minimize the hardness difference between phases.

\section{Conclusions}

(1) From $0.005 \mathrm{~s}^{-1}$ to $0.5 \mathrm{~s}^{-1}$, both the total elongation and the reduction in area increase with the strain rate.

(2) More than $85 \%$ of cracks formed between ferrite and austenite, and no less than $70 \%$ of cracks tips propagated between ferrite and austenite.

(3) Increasing the strain rate from $0.005 \mathrm{~s}^{-1}$ to $0.5 \mathrm{~s}^{-1}$ promoted dynamic recrystallization in the austenite and improved the number fraction of LAGBs in the ferrite.

(4) Higher strain rate lowers the difference between ferrite and austenite in microhardness. Therefore, the hot ductility was improved.

(5) For 2205 DDS, the suggested strain rate is $0.5 \mathrm{~s}^{-1}$ and above to avoid surface and edge cracking during hot forging or hot rolling.

\section{Data Availability}

The hot tension test and electron backscatter diffraction data used to support the findings of this study have not been made available because these data contain a lot of unanalyzed information and will be studied in the future.

\section{Conflicts of Interest}

The authors declare that there are no conflicts of interest regarding the publication of this paper.

\section{Acknowledgments}

The authors gratefully acknowledge the financial support of the project from the Natural Science Foundation-Steel and Iron Foundation of Hebei Province (no. E2017203041) and the National Natural Science Foundation of China (no. 51505416).

\section{References}

[1] J. Lv, T. Liang, C. Wang, and T. Guo, "Influence of sensitization on passive films in AISI 2205 duplex stainless steel," Journal of Alloys and Compounds, vol. 658, pp. 657-662, 2016.

[2] J. D. Tucker, M. K. Miller, and G. A. Young, "Assessment of thermal embrittlement in duplex stainless steels 2003 and 2205 for nuclear power applications," Acta Materialia, vol. 87, pp. 15-24, 2015.

[3] G. Martin, M. Véron, B. Chéhab et al., "Duplex stainless steel microstructural developments as model microstructures for hot ductility investigations," Solid State Phenomena, vol. 172-174, pp. 350-355, 2011.

[4] Z.-H. Feng, J.-Y. Li, and Y.-D. Wang, "Mechanism of hotrolling crack formation in lean duplex stainless steel 2101,"
International Journal of Minerals, Metallurgy, and Materials, vol. 23, no. 4, pp. 425-433, 2016.

[5] G. W. Fan, J. Liu, P. D. Han, and G. J. Qiao, "Hot ductility and microstructure in casted 2205 duplex stainless steels," $M a$ terials Science and Engineering: A, vol. 515, no. 1-2, pp. 108112, 2009.

[6] S. Patra, A. Ghosh, V. Kumar, D. Chakrabarti, and L. K. Singhal, "Deformation induced austenite formation in as-cast 2101 duplex stainless steel and its effect on hot-ductility," Materials Science and Engineering: A, vol. 660, pp. 61-70, 2016.

[7] Y. Zhao, Y. Wang, S. Tang, W. Zhang, and Z. Liu, "Edge cracking prevention in 2507 super duplex stainless steel by twin-roll strip casting and its microstructure and properties," Journal of Materials Processing Technology, vol. 266, pp. 246-254, 2019.

[8] J. Han, J.-P. Sun, Y. Han, and H. Liu, "Hot workability of the as-cast $21 \mathrm{Cr}$ economical duplex stainless steel through processing map and microstructural studies using different instability criteria," Acta Metallurgica Sinica (English Letters), vol. 30, no. 11, pp. 1080-1088, 2017.

[9] M. Ma, H. Ding, Z. Tang, J. Zhao, Z. Jiang, and G. Li, "Effect of strain rate and temperature on hot workability and flow behaviour of duplex stainless steel," Ironmaking \& Steelmaking, vol. 43, no. 2, pp. 88-96, 2016.

[10] M. Faccoli and R. Roberti, "Study of hot deformation behaviour of 2205 duplex stainless steel through hot tension tests," Journal of Materials Science, vol. 48, no. 15, pp. 51965203, 2013.

[11] Z. Wang, Q. Meng, M. Qu, Z. Zhou, B. Wang, and W. Fu, "Effect of strain rate on hot ductility behavior of a high nitrogen Cr-Mn austenitic steel," Metallurgical and Materials Transactions A, vol. 47, no. 3, pp. 1268-1279, 2016.

[12] A. Dehghan-Manshadi and P. D. Hodgson, "Effect of $\delta$-ferrite co-existence on hot deformation and recrystallization of austenite," Journal of Materials Science, vol. 43, no. 18, pp. 6272-6277, 2008.

[13] T. W. Wong, A. Hadadzadeh, M. J. Benoit, and M. A. Wells, "Impact of homogenization heat treatment on the high temperature deformation behavior of cast AZ31B magnesium alloy," Journal of Materials Processing Technology, vol. 254, pp. 238-247, 2018. 


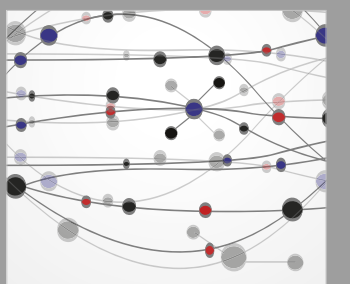

The Scientific World Journal
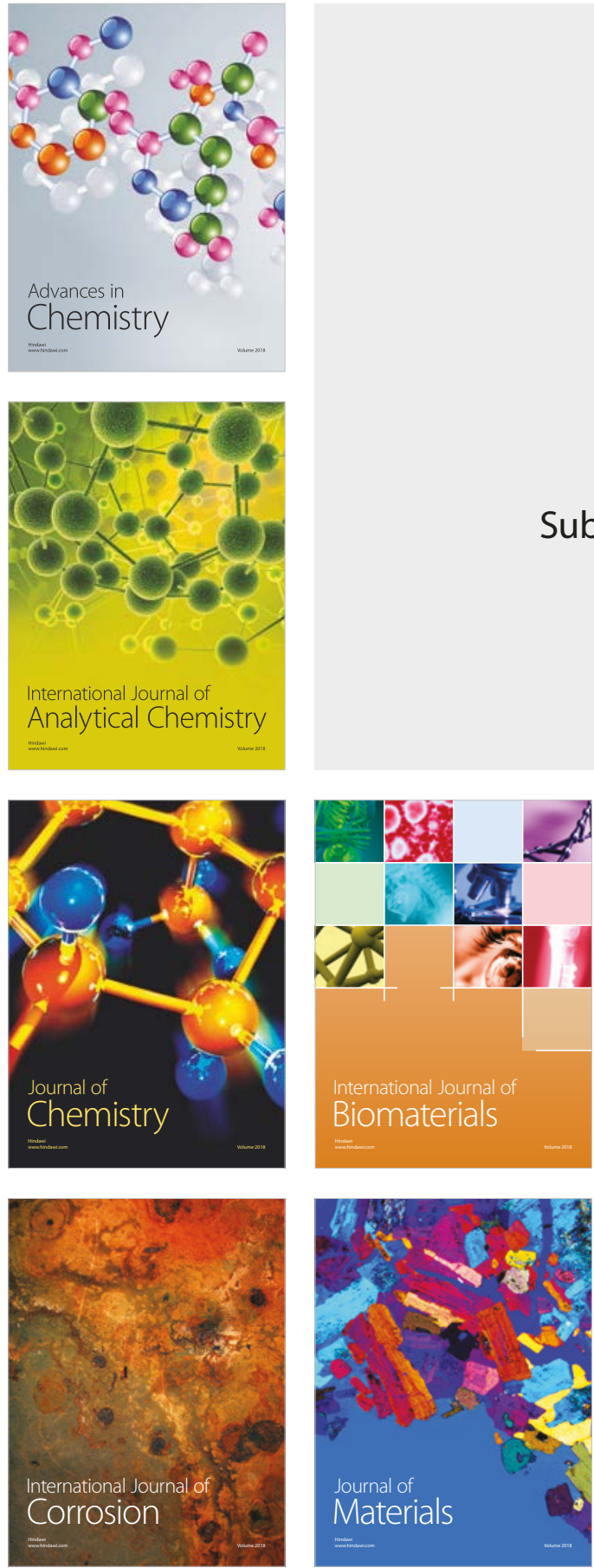

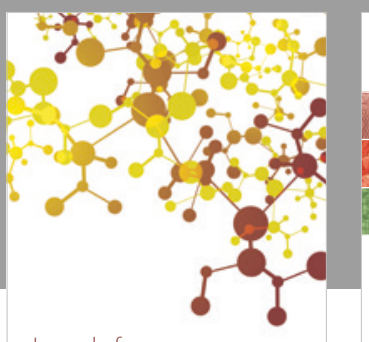

Journal of

Applied Chemistry
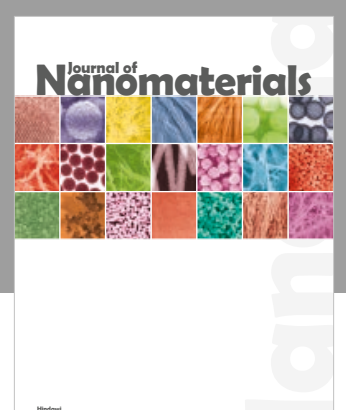

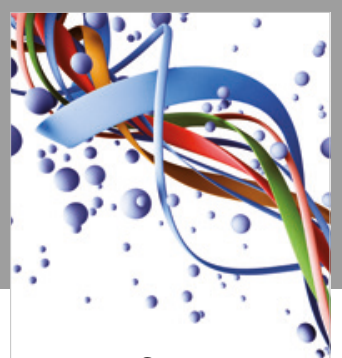

Scientifica

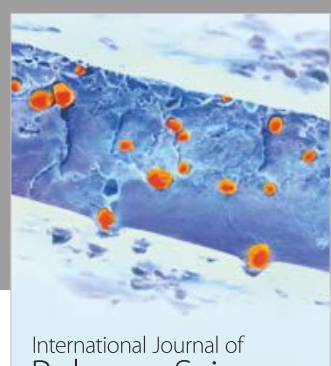

Polymer Science

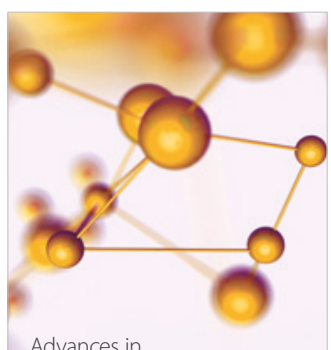

Physical Chemistry
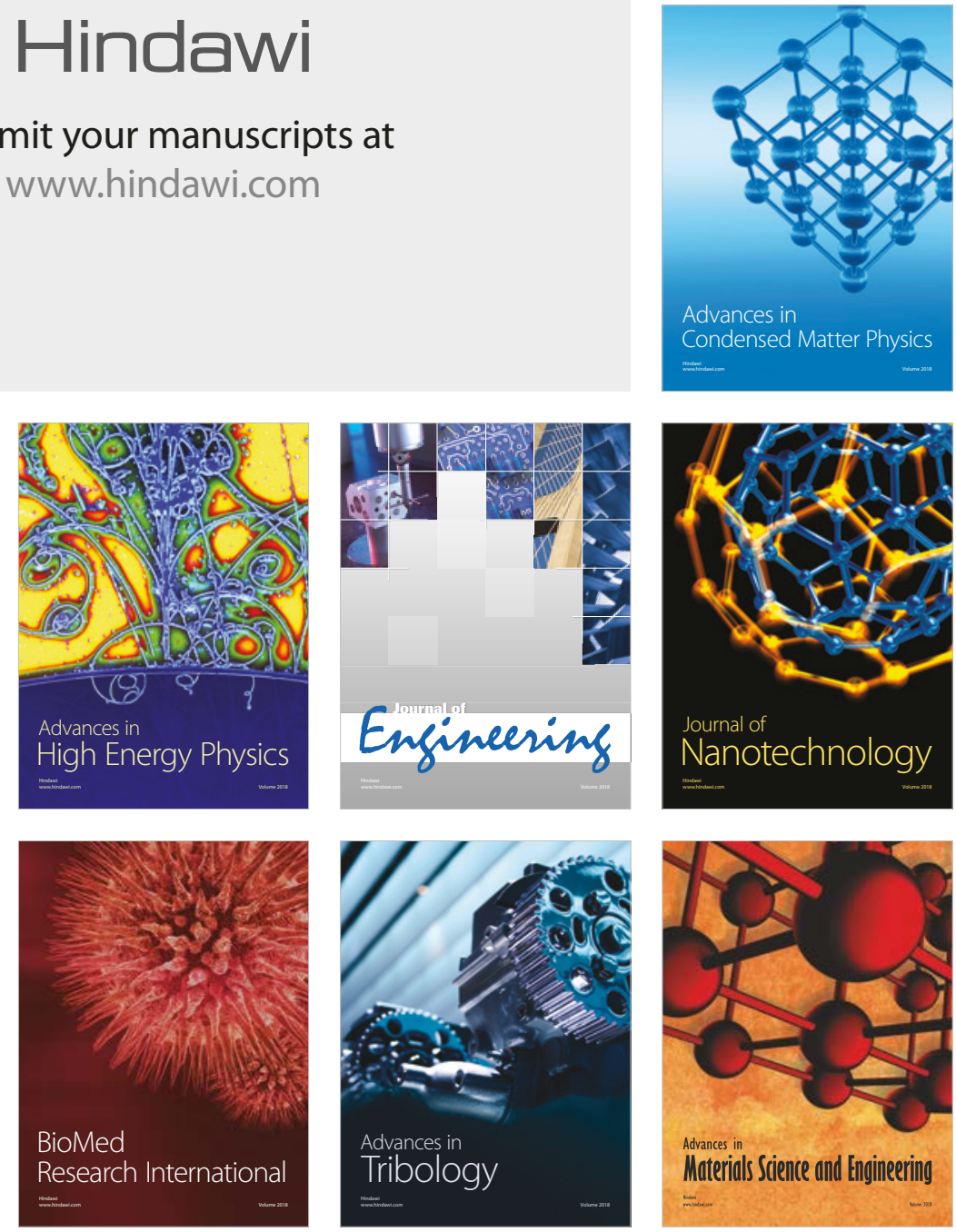